\title{
Opting for Living-Apart-Together and Cohabitation Relationships in people 50+: A Longitudinal Analysis'
}

\author{
Anna Ševčíková, Dana Seryjová Juhová, Adam Ťápal, \\ Lukas Blinka, Jaroslav Gottfried
}

\begin{abstract}
Despite a growing body of research on later-life relationships, there are still only a limited number of explorative longitudinal studies that have investigated the factors responsible for the establishment of either a Living-Apart-Together (LAT) arrangement or a cohabitation relationship. Two waves of data collection by the Survey of Health, Ageing and Retirement in Europe (2014/2015-2017; $\mathrm{N}=12,155 ; \mathrm{M}_{\text {age }}=71.96 ; 76.3 \%$ women) were analyzed with a special focus on family, dwelling, and financial constraints. Those who were male, younger, and had more children were more likely to enter into a LAT arrangement or a cohabitation relationship than to remain unpartnered. More rooms and fewer years spent in the accommodation raised the odds to partner. LAT persons were slightly older than those in cohabitation relationships. No other factors influenced the form of living arrangement, which indicates that factors other than financial constraints and family responsibilities affect later-life LAT or cohabitation relationship formation.
\end{abstract}

KEYWORDS relationship formation, partnering, Living-Apart-Together relationships, cohabitation, ageing, Socioemotional Selectivity Theory, SHARE project

\section{Introduction}

In Europe, the number of people aged 50 and over, as a proportion of the total population, is increasing due to declining fertility rates and rising life expectancy (Eurostat 2017a). Each younger cohort is expected to live longer and better maintain good health (Eurostat 2017b). But there is also a noteworthy proportion of people who enter later life without a partner and consider partnering in order to avoid the risk of emotional loneliness (Koren and Simhi 2016;

Sociálni studia / Social Studies 1/2022. Pp. 131-144. ISSN 1214-813X. https://doi.org/10.5817/SOC2021-14669

1 This study was supported by research grant no. 17-11384S from the Czech Science Foundation. The SHARE data collection was primarily funded by the European Commission through FP5 (QLK6-CT-2001-00360), FP6 (SHARE-I3: RII-CT-2006-062193, COMPARE: CIT5-CT-2005-028857, SHARELIFE: CIT4-CT-2006-028812), andFP7 (SHARE-PREP: N²11909, SHARE-LEAP: N²27822, SHARE M4: N²61982). Additional funding came from the German Ministry of Education and Research, the Max Planck Society for the Advancement of Science, the US National Institute on Aging (U01_AG09740-13S2, P01_AG005842, P01_AG08291, P30_AG12815, R21_AG025169, Y1-AG-4553-01, IAG_BSR06-11, OGHA_04-064, HHSN271201300071C), and various national funding sources, which are gratefully acknowledged (see www.share-project.org). 
Schimmele and $\mathrm{Wu}$ 2016). However, later-life relationship formation constitutes a challenge in many aspects.

\section{Later-life Relationship Formation}

Relationship formation in later life generally differs from partnering at a younger age and it produces specific challenges. It may require the re-organization of established social relations (e.g. with direct family members, step family members); it endangers independence (e.g. older people have their own established households); and it raises questions about the potential demands of caring for a partner whose mental and physical health is likely to deteriorate with age (de Jong Gierveld 2015; Karlsson and Borrell 2002; Koren and Simhi 2016). Therefore, some studies have indicated that older people may choose bonds that allow both long-term intimacy and a significant degree of autonomy (de Jong Gierveld and Merz 2013; Duncan et al. 2013; Turcotte 2013). A Living-Apart-Together (LAT) relationship is one type of this flexible bond.

\section{LAT Relationships}

The LAT relationship represents a family form in which partners are considered to be a couple despite keeping separate households. Later-life LAT relationships are not the same as LAT relationships formed at a younger age. Although older partners share a commitment, they are less willing to transform the LAT relationship into cohabitation than younger adults, for whom LAT relationships more likely represent a temporary living arrangement (Duncan et al. 2013; Kobayashi, Funk, and Khan 2017; Levin 2004; Régnier-Loilier, Beaujouan, and Villeneuve-Gohalp 2009; Reimondos, Evans, and Gray 2011; Turcotte 2013). Therefore, later-life LAT relationships tend to last longer (Duncan et al. 2013). However, the incidence of this relationship form in older age is still rather rare, ranging from $2.1 \%$ to $7 \%$ in the Netherlands, Sweden, Canada, and the United States (de Jong Gierveld 2015; Lewin 2017; Öberg and Bildtgard, cited in de Jong Gierveld 2015; Turcotte 2013). In this respect, cohabitation and remarriage constitute more common family forms for older couples, with remarriage the more prevalent option than cohabitation (Brown et al. 2016; De Jong Gierveld and Merz 2013; Lewin 2017; Wu, Schimmele, and Ouellet 2014). There is also a growing preference for cohabitation within younger cohorts (Schimmele and Wu 2016). However, very few studies have adopted a longitudinal perspective for studying the factors that influence LAT and cohabitation relationships in later life, and they have also failed to explore the facilitation of partnering in either form rather than staying unpartnered in later life.

\section{Reasons for LAT Relationships in Later Life}

Previous studies suggest that later-life partnering is a complex phenomenon in which one's socioeconomic situation, opportunities to meet a new partner (e.g. the gender gap in the dating market favouring older men to (re)partner), and health status play relevant roles (Brown et al. 2016; de Jong Gierveld 2004; Schimmele and Wu 2016; Vespa 2012; Wu 
et al. 2015). With respect to LAT partnering, it has been shown that the need to balance intimacy with maintaining autonomy and independence may motivate individuals to enter into and stay in later-life LAT relationships (Očadlíková 2009). This might be particularly true for women who prefer a LAT relationship due to the desire to avoid a gendered household, i.e. a traditional gendered division of labour (Duncan et al. 2013; Funk and Kobayashi 2016; Upton-Davis 2012). Also, the preference may arise from more profound psychosocial changes that older people undergo in later life. According to the theory of socioemotional selectivity, these changes constitute a re-orientation from knowledge-related goals to emotion-related goals (Carstensen, Isaacowitz, and Charles 1999). People significantly revise their goals when time horizons become shorter (i.e. as they grow older). They find it important to regulate emotions and focus on what is most important, typically meaningful relationships from which they derive increasing satisfaction (ibid.). Applying Carstensen's assumptions on later-life relationship formation, LAT relationships may represent a good compromise between the need for relational intimacy while preserving both existing commitments and emotionally valuable social contacts with children, grandchildren, and close friends (de Jong Gierveld and Merz 2013; Malta and Farquharson 2014; Ševčíková, Lichá, and Skařupová 2018). In this vein, we hypothesize that, when controlling for factors that strongly influence partnering in later life (namely gender, age, socioeconomic situation, perceived health, children), those who remain unpartnered and those who opt for a LAT or cohabitation relationship may differ prior to relationship formation in the following ways: (1) unpartnered persons perceive more family responsibilities and commitments in comparison to those who partner in either relationship form, and (2) those who opt for a LAT living arrangement have more perceived family responsibilities and commitments compared to those who enter into a cohabitation relationship.

Similarly, later-life relationship formation may require one of the partners to leave his or her household and potentially disrupt emotionally valuable social contacts so that the new couple can live together (de Jong Gierveld 2002). Applying the theory of socioemotional selectivity (Carstensen et al. 1999) to later-life relationship formation, older people might find it risky to leave their place of residence and its associated emotional bonds. Worries about disrupting the bonds connected to place of residence may discourage individuals from partnering in later life. We hypothesize that those who remain unpartnered and opt for a LAT or cohabitation relationship may differ at the initial level of bonding to their residence (i.e. before partnering) in the following ways: (1) unpartnered persons have stronger bonds to their place of residence compared to those who partner in either relationship form, and (2) persons opt for a LAT living arrangement because of stronger bonds to their place of residence in comparison with those who establish a cohabiting relationship.

Given the preference in the older cohort for marriage and a cohabitation relationship and the low prevalence of later-life LAT relationships (Brown et al. 2016; De Jong Gierveld and Merz 2013; Lewin 2017), the preference for a LAT living arrangement as an alternative may also be influenced by the level of openness towards less conventional relationship forms. Level of education often serves as a proxy for openness, and has consistently been found to be associated with socioeconomic status and with a liberal political and social orientation (Schoon et al. 2010). Research on the general population has demonstrated that more educated people are more likely to live in LAT relationships (Strohm et al. 2009; 
Turcotte 2013). Greater openness towards alternative living arrangements may enhance opting for a LAT relationship rather than for a more legitimate type of cohabitation, such as remarriage or unmarried cohabitation. Accordingly, we hypothesize that those who opt for a less conventional relationship form - a LAT living arrangement - are more likely to report a higher level of education compared to those who remain unpartnered or those who cohabit. With respect to openness to alternative living arrangements in later life, there is no satisfactory justification that unpartnered persons and people in cohabitation relationships would differ in their level of education.

Lastly, several studies show that, for some older people, later-life relationship formation and, particularly, opting for a LAT living arrangement, may be the result of personal resource constraints rather than the reorientation of emotional goals or specific values (Vespa 2012). Specifically, limited financial and housing assets have been found to constitute a barrier for partnering in later life (Vespa 2012), and financial challenges (e.g. losing financial benefits, losing financial independence, potential care cost), including space limits in households, are often discussed as reasons for considering a LAT relationship (Duncan et al. 2012; Kobayashi et al. 2017; Régnier-Loilier et al. 2009; Turcotte 2013). We propose to test the assumptions that (1) older people who enter into a LAT relationship are more likely to experience resource constraints before partnering than those who decide to cohabit with their partners, and (2) those who partner in either relationship form are less likely to report resource constraints than persons who remain unpartnered in later life.

\section{Research Aim}

In this study, we have introduced selected potential factors that may shape relationship formation and living arrangements in later life. These include education level and barriers associated with family bonds, dwelling, and resource constraints. However, these factors were studied using a cross-sectional research design. To overcome this limit, we aim to explore them from a longitudinal perspective.

\section{Method}

\section{Data Description}

The data come from the Survey of Health, Ageing and Retirement in Europe (SHARE). The survey is based on probability samples and was conducted in European countries and Israel (18 countries in total). SHARE is a longitudinal panel study of people aged 50 and over who regularly lived in the respective participating country at the time of data collection. This study is specifically designed to best capture the actual characteristics of the older population by having a large sample with no age limit at the top of the age range ${ }^{2}$. The last two data

The Generations and Gender Survey provides comparable, albeit outdated, data from 2008-09. Moreover, this project was not specifically designed to monitor the older population because the ages ranged from 18 to 79 . 
collections of the seven waves, which were selected for this study, were conducted in 201415 (Wave 6) and 2017 (Wave 7) (Börsch-Supan 2018). Participants were excluded from the sample if (1) they were unreachable at home during the entire survey period, (2) they were unable to speak in one of the official national languages, or (3) they were born after 1954. Recruitment was done by telephone or in person at the participant's home address. Computerassisted personal interviews were used for data collection. The SHARE study has been reviewed and approved by the Ethics Council of the Max Planck Society (Wave 4 and later). All participants signed an informed consent form (Malter and Börsch-Supan 2017).

Sample and the Identification of Respondents with No Partner as a Relationship Status in Wave 6 (Time 1)

For research purposes, we selected only those who were unpartnered in Wave 6 for the follow-up analyses. To identify these respondents, we used the following variables: (1) marital status with response options "married", "partnered", "married, but living separated", "divorced", and "widowed"; (2) having a partner in their household with a negative or positive response option; and (3) having a partner outside of their household with a false or positive response option. After combining the key information, our study sample included only those who participated in the sixth and seventh waves of data collection; those who indicated no partner in their household or outside of the household; and those who simultaneously indicated being "never married", "divorced", or "widowed" as their family status $(\mathrm{n}=12,155$ participants; age $e_{\text {mean }}=71.96 ; \mathrm{SD}_{\text {age }}=10.47 ; 75.3 \%$ women). The participants who were unpartnered in Wave 6 (Time 1) were followed to Wave 7 (Time 2). The remaining persons who did not meet these criteria were excluded $(n=39,594)$. Respondents with missing or contradictory information were also excluded $(n=415)$.

\section{Measurements}

Relationship status and over-time changes were measured using two variables administrated in Wave 7 (Time 2): (1) having a partner in a household with a false or positive response option, and (2) having a partner outside of their household with a false or positive response option. All those whose relationship status remained unchanged were treated as unpartnered $(=0)$. All those who indicated having a partner outside of their household and no partner in the household in Wave 7 were treated as being newly partnered with a Living-Apart-Together relationship status $(=1)$, except for those married but living separately, who were excluded from the analysis. The remaining respondents who had a partner in their household and not outside of the household in Wave 7 were assigned a cohabitation relationship status $(=2)$. Marriage and cohabitation were not differentiated as distinct family forms in this study due to the small sample size of the cohabitation category (see Table 1). 


\section{Variables Measured in Wave 6 (Time 1)}

Bonds to family and dwelling: This cluster of factors included variables that measured the extent of perceived family responsibilities, the number of family-related members supported financially, the number of years spent in a household, and household ownership status.

Perceived family responsibilities: Respondents were asked "How often do you think that family responsibilities prevent you from doing the things you want to do?" The response scale ranged from often $(=1)$ to never $(=4)$.

Number of children: A variable indicating the number of children the participant had.

Number of family-related members supported financially: This category was created from a number of questions that mapped to whom the respondent had given at least 250 Euro in the preceding 12 months. Respondents were asked "Now please think about the last twelve months. Not counting any shared housing or shared food, have you provided any financial or material gift or support to any person inside or outside this household amounting to 250 Euro or more?" Possible answers were Yes or No. Another question was "To whom did you provide a financial gift or assistance?" Responses included 36 options that ranged from familyrelated members (e.g. a mother, a child, a grandchild) to non-family members (e.g. a friend, a (ex-)colleague). The ad hoc variable included a number of family-related members that respondents financially supported within the preceding 12 months. The minimum was zero persons and maximum was three persons.

Years living in household: Respondents were asked to indicate the number of years they had lived in their home.

Household ownership status: Respondents were asked about their relationship to their household. Response options included owner, member of a cooperative, tenant, subtenant, and rent-free. These options were re-categorized into tenancy-type housing $(=1)$ and nontenancy type $(=0$, such as ownership or membership in a cooperative).

Resource constraints: This cluster had variables that measured the number of overall rooms in the household and the ability to make ends meet.

Number of rooms in household: Respondents were asked to indicate the number of rooms specifically for personal use in their household.

Able to make ends meet: Respondents were asked "Is your household able to make ends meet?" Responses ranged from with great difficulty $(=1)$ to easily $(=4)$.

Education: This factor was used as a proxy for openness towards alternative relationship forms.

Years of education. This variable refers to the reported number of years that the respondent had spent in full-time education, assuming that more years indicated higher education. The minimum was 0 years and the maximum was 25 years.

Health: In order to account for health issues which could possibly interfere with the respondent's personal life, we decided to incorporate the health factor into our analysis. We preferred a subjective indicator, because the self-perceived severity of health issues could reflect the impact of health on one's own life and romantic relationships better than an objective indicator.

Self-perceived health - US scale: This scale consists of only one item, which reads: "In general, would you say your health is ...". Respondents were asked to choose one from the following answers: excellent $(=1)$, very $\operatorname{good}(=2)$, $\operatorname{good}(=3)$, fair $(=4)$, and poor $(=5)$. 


\section{Data Analysis}

Data analysis was conducted in Mplus8. Given the low rates of later-life relationship formation (see Table 1), we decided to use the entire SHARE sample without analyzing potential differences between individual countries. To address the hierarchical structure of the data (i.e. respondents were nested within countries), we conducted multinomial and logistic regressions with a sandwich estimator to provide corrections to the standard errors (Asparouhov and Muthén 2005, 2006). This approach is useful for cluster sampling with no focus on multilevel analysis (Asparouhov and Muthén 2005). Only in the case of the original education variable - for which approximately 200 participants had a missing value - we used its imputed variable, which was available in the SHARE data set from Wave 6.

\section{Results}

Table 1 contains a description of the three participant groups - LAT, Cohabitation, and Unpartnered - through the variables used in subsequent regression analyses. Note that all of the variables concern the sixth wave of data collection (i.e. before the change of relationship status).

Table 1: Descriptive Statistics of LAT, Cohabiting/Married, and No Partner in Wave 6 (Before the Change in Relationship Status)

\begin{tabular}{|l|c|c|c|}
\hline & LAT & $\begin{array}{c}\text { Cohabiting/ } \\
\text { Married }\end{array}$ & Unpartnered \\
\hline$N$ & 509 & 125 & 11521 \\
\hline Age & & & \\
\hline of men & $64.90(8.84)$ & $63.64(9.09)$ & $72.37(10.40)$ \\
\hline Marital status ${ }^{a}$ & $225(44.2 \%)$ & $51(40.8 \%)$ & $2705(23.5 \%)$ \\
\hline Divorced & & & \\
\hline Widowed & $237(46.6 \%)$ & $50(40.0 \%)$ & $2607(22.6 \%)$ \\
\hline Never married & $166(32.6 \%)$ & $42(33.6 \%)$ & $6934(60.2 \%)$ \\
\hline Number of children & $106(20.8 \%)$ & $33(26.4 \%)$ & $1980(17.2 \%)$ \\
\hline Years of education & $1.99(1.34)$ & $2.02(1.25)$ & $2.01(1.45)$ \\
\hline Able to make ends meet & $12.12(4.20)$ & $11.18(4.02)$ & $10.31(4.47)$ \\
\hline Self-perceived health & $2.86(1.05)$ & $2.66(1.05)$ & $2.64(1.05)$ \\
\hline Rooms in household & $2.90(1.07)$ & $3.07(1.25)$ & $3.41(1.04)$ \\
\hline Years in household & $3.43(1.63)$ & $3.62(1.62)$ & $3.24(1.58)$ \\
\hline Household ownership status (tenancy) & $21.74(17.34)$ & $19.27(16.56)$ & $29.28(19.86)$ \\
\hline Family responsibilities & $34.7 \%$ & $29.7 \%$ & $33.1 \%$ \\
\hline Financially supported family-related members & $0.51(0.89)$ & $0.33(0.65)$ & $0.33(0.73)$ \\
\hline
\end{tabular}

Note: If not indicated otherwise, the values are arithmetic means with standard deviations in parentheses.

${ }^{\mathrm{a}} x^{2}(6)=232.97, p<.001$, Cramer's $V=.01$.

b 39 respondents were never married after relationship disruption. 
We conducted a multinomial regression with the unpartnered group as the reference category. Subsequently, we conducted a logistic regression analysis where the two nonsingle relationship categories (LAT and Cohabitation) were compared, using the latter as the reference category. Although some demographic variables, such as age and years spent living in the current household, are likely to be correlated, none of the variance inflation factors were high enough to warrant worries about the attenuation of independent effects.

Table 2: Results of Multinomial and Logistic Regression

\begin{tabular}{|c|c|c|c|c|c|c|}
\hline \multirow[b]{3}{*}{ Coefficient } & \multicolumn{4}{|c|}{$\begin{array}{l}\text { Multinomial regression ( } N=8147 ; \text { Reference } \\
\text { category - Unpartnered, } n=7657)\end{array}$} & \multirow{2}{*}{\multicolumn{2}{|c|}{$\begin{array}{c}\text { Logistic regression }(n=490) \\
\text { LAT vs. Cohabiting/Married } \\
\text { (Reference category) }\end{array}$}} \\
\hline & \multicolumn{2}{|c|}{$\operatorname{LAT}(n=397)$} & \multicolumn{2}{|c|}{$\begin{array}{l}\text { Cohabiting/Married } \\
\quad(n=93)\end{array}$} & & \\
\hline & Value & OR $(95 \% \mathrm{Cl})$ & Value & OR $(95 \% \mathrm{Cl})$ & Value & OR $(95 \%$ Cl) \\
\hline \multicolumn{7}{|l|}{ Model 3} \\
\hline Intercept / Thresholds & $1.80^{*}$ & & $2.32^{*}$ & & 0.66 & \\
\hline Age & $-0.06^{*}$ & $\begin{array}{c}0.95 \\
(0.94 ; 0.95)\end{array}$ & $-0.08^{*}$ & $\begin{array}{c}0.92 \\
(0.90 ; 0.94)\end{array}$ & $0.03^{\dagger}$ & $\begin{array}{c}1.03 \\
(1.00 ; 1.05)\end{array}$ \\
\hline Woman (vs. Man) & $-0.66^{*}$ & $\begin{array}{c}0.52 \\
(0.40 ; 0.64)\end{array}$ & $-0.57^{\dagger}$ & $\begin{array}{c}0.57 \\
(0.33 ; 0.89)\end{array}$ & 0.05 & $\begin{array}{c}1.06 \\
(0.55 ; 1.82)\end{array}$ \\
\hline Years of education & 0.02 & $\begin{array}{c}1.02 \\
(0.99 ; 1.05)\end{array}$ & -0.04 & $\begin{array}{c}0.97 \\
(0.91 ; 1.02)\end{array}$ & 0.05 & $\begin{array}{c}1.05 \\
(0.97 ; 1.12)\end{array}$ \\
\hline $\begin{array}{l}\text { Able to make ends } \\
\text { meet }\end{array}$ & 0.08 & $\begin{array}{c}1.08 \\
(0.99 ; 1.17)\end{array}$ & -0.04 & $\begin{array}{c}0.96 \\
(0.75 ; 1.19)\end{array}$ & 0.12 & $\begin{array}{c}1.13 \\
(0.83 ; 1.46)\end{array}$ \\
\hline Number of children & $0.08^{+}$ & $\begin{array}{c}1.08 \\
(1.01 ; 1.15)\end{array}$ & $0.11^{\dagger}$ & $\begin{array}{c}1.11 \\
(1.02 ; 1.20)\end{array}$ & -0.04 & $\begin{array}{c}0.97 \\
(0.84 ; 1.08)\end{array}$ \\
\hline Self-perceived health & $-0.20^{*}$ & $\begin{array}{c}0.82 \\
(0.73 ; 0.90) \\
\end{array}$ & 0.04 & $\begin{array}{c}1.04 \\
(0.78 ; 1.33) \\
\end{array}$ & -0.23 & $\begin{array}{c}0.80 \\
(0.57 ; 1.06) \\
\end{array}$ \\
\hline Rooms in household & $0.05^{\dagger}$ & $\begin{array}{c}1.05 \\
(1.00 ; 1.10)\end{array}$ & $0.14^{*}$ & $\begin{array}{c}1.16 \\
(1.05 ; 1.25)\end{array}$ & -0.12 & $\begin{array}{c}0.89 \\
(0.77 ; 1.00)\end{array}$ \\
\hline Years in household & $-0.01 *$ & $\begin{array}{c}0.99 \\
(0.98 ; 0.99)\end{array}$ & $-0.03^{*}$ & $\begin{array}{c}0.97 \\
(0.96 ; 0.99)\end{array}$ & 0.01 & $\begin{array}{c}1.01 \\
(1.00 ; 1.03)\end{array}$ \\
\hline $\begin{array}{l}\text { Household ownership } \\
\text { status' }\end{array}$ & -0.04 & $\begin{array}{c}0.96 \\
(0.73 ; 1.21)\end{array}$ & -0.28 & $\begin{array}{c}0.75 \\
(0.54 ; 1.00)\end{array}$ & 0.21 & $\begin{array}{c}1.24 \\
(0.81 ; 1.76)\end{array}$ \\
\hline Family responsibilities & 0.08 & $\begin{array}{c}1.09 \\
(0.98 ; 1.19) \\
\end{array}$ & 0.04 & $\begin{array}{c}1.04 \\
(0.77 ; 1.34) \\
\end{array}$ & 0.05 & $\begin{array}{c}1.05 \\
(0.73 ; 1.41) \\
\end{array}$ \\
\hline $\begin{array}{l}\text { Financially supported } \\
\text { fam. }^{2} \text { members }\end{array}$ & 0.16 & $\begin{array}{c}1.17 \\
(1.00 ; 1.33)\end{array}$ & -0.15 & $\begin{array}{c}0.86 \\
(0.67 ; 1.07)\end{array}$ & 0.34 & $\begin{array}{c}1.40 \\
(0.99 ; 1.88)\end{array}$ \\
\hline$R^{2}$ & & & & & 0.10 & \\
\hline
\end{tabular}

Note: $*=\mathrm{p}<.01 ;{ }^{\dagger}=\mathrm{p}<.05$. No sample weights were used.

${ }^{1} 0=$ owner; $1=$ tenant

${ }^{2} \mathrm{Fam} .=$ family related 
Table 2 presents the parameter estimates, their associated odds ratios, and $95 \%$ confidence intervals for all of the analyzed models. In the model of the multinomial regression, people who entered into LAT or cohabitation relationships were found to be younger, have more children, and be more likely to be male than those who remained unpartnered. In addition, people who entered into a LAT relationship were more likely to report better self-perceived health than the unpartnered respondents. The non-single categories also tended to reside in households with slightly more rooms, and spent fewer years in their accommodation than the unpartnered group. With respect to the logistic regression, we did not identify any factors that would efficiently predict the type of relationship a respondent would enter into. Neither the ownership of the household nor the perceived amount of family responsibilities nor the number of financially supported family members discriminated between the LAT and cohabiting groups. LAT persons were only slightly older than those in cohabitation relationships.

\section{Discussion}

This study used SHARE data to examine whether the outcomes of later-life relationship formation may be explained by family, bonds to dwelling place, resource constraints, and educational level as a proxy for openness to an alternative living arrangement, such as a LAT relationship.

We found no evidence for substantial differences among the groups with regard to the perceived level of family responsibilities and commitments, after controlling for the number children. In comparison with those who remained unpartnered, those who entered a relationship reported having slightly more offspring. This finding is in line with prior research (De Jong Gierveld and Merz 2013). Although qualitative studies have found that older people, in their own telling, take into consideration their children's opinions on laterlife partnering (Malta and Farquharson 2014; Ševčíková et al. 2018), the selected indicators of perceived family responsibilities and commitments failed to corroborate this. It is also possible that perceived family constraints could not be pronounced in association to later-life relationship formation. Specifically, this was a prospective study so that older people may have found it valuable to support their family members and may not have necessarily felt ambiguous about their family responsibilities and commitments until/unless they encountered a new partner.

The results support the hypothesis that (1) unpartnered persons have stronger bonds to their dwelling compared to those who partner in either relationship form; but failed to show convincing evidence that (2) persons opt for a LAT living arrangement because of stronger bonds to their dwelling in comparison to those who establish a cohabiting relationship. Despite controlling for age, those in non-single categories tended to spend fewer years in their accommodations than unpartnered persons. Although these findings support applying the principles of socioemotional selectivity theory (Carstensen et al. 1999) on later-life relationship formation (i.e. older people might find it risky to leave their place of dwelling and sacrifice their emotional bonds to it), this interpretation should be taken with caution, 
primarily due to the fact that the difference between LAT and cohabiting (married) persons in years spent in their own households was rather negligible.

The findings about resource constraints related to partners in later life and the establishment of cohabiting relationships were inconclusive. Although respondents in all the compared groups did not differ in their ability to make ends meet, those in nonsingle categories reported more rooms at their disposal compared to those who remained unpartnered. The latter result may correspond to prior research, according to which greater housing wealth increases the chances of relationship formation in later life (Vespa 2012). However, it is worth mentioning that differences in the number of rooms within the household according to relationship status were not dramatic and more research is needed to comprehensively examine the economic determinants of later-life relationship formation. Moreover, our analysis provided no support for the assumption that older people who enter into a LAT relationship are more likely to experience dwelling and financial constraints before partnering than those who decide to cohabit with their partners. The findings suggest that these groups are likely to be comparable and the way resource constraints were conceptualized in this study did not show it to be relevant for understanding the different trajectories in later-life relationship formation (a LAT relationship versus more traditional relationship forms). Given the fact that later-life LAT relationships are likely to be stable (Duncan et al. 2013; Levin 2004; Régnier-Loilier et al. 2009; Reimondos et al. 2011; Turcotte 2013), the lack of effect from resource constraints might indicate that older people tend to justify staying in LAT living arrangements for different reasons. For instance, choice and the need for autonomy may be at play (Connididis, Borell, and Karlsson 2017).

The challenge to identify the factors responsible for differences in later-life relationship formation was apparent in another finding. Our results provided no support for the assumption that people with more education are more likely to enter a LAT relationship rather than a cohabitation relationship. The data from the SHARE survey did not replicate findings from research conducted on general populations, according to which more educated people are more likely to live in LAT relationships (Strohm et al. 2009; Turcotte 2013). It is an open question as to the extent that older generations vary in the level of education as compared to younger generations, for which LAT relationships are temporary solutions during university studies and temporary labour migration (Duncan et al. 2013, Régnier-Loilier et al. 2009; Reimondos et al. 2011; Turcotte 2013). It is also worth mentioning that educational level was conceptualized as a proxy for a more liberal value orientation (see Schoon et al. 2010) and thus for a greater openness to an alternative living arrangement, such as a LAT relationship. This may constitute a limit for our study that could be overcome in future research by using more focused instruments to measure liberal political and social orientation.

Although this study provides a limited understanding for why some older people establish LAT relationships while others enter into cohabitation or marriage, the findings largely corroborate prior research for the predictors of later-life relationship formation. Akin to this study, male gender, lower age, and better health status have been shown to be the most reliable predictors of later-life relationship formation (Brown et al. 2016; de Jong Gierveld 2004; Schimmele and Wu 2016; Vespa 2012; Wu et al. 2015). Lower age and better health are factors that may be associated with attractiveness and minimized risks for care 
obligation (Connidis et al. 2017). More precisely, advanced age may make an individual less eligible to gain a partner because the remaining length of time for relatively good health is uncertain (Koren and Simhi 2016; Ševčíková et al. 2018). Moreover, due to the longer life expectancy for women, older women face a structural disproportion in the dating and marriage market, thus lowering their chances of finding a new partner (Brown et al. 2016; de Jong Gierveld 2004; Schimmele and Wu 2016; Wu et al. 2014). Nonetheless, it may be surprising that better health predicted partnering only in the form of a LAT relationship when compared to those who remained unpartnered. A possible explanation could be that staying in a LAT relationship means mutual visitation, travelling, and potentially meeting outside of one's household. These activities may require good self-rated health. It is also possible that better health may allow for the fulfilment of the main function of later-life LAT relationships, which is to have someone with whom older people may share hobbies, spend leisure time, and have fun (Benson and Coleman 2016; Bildtgård and Öberg 2015; Koren 2014, 2015).

Lastly, the study showed that LAT persons were only slightly older than respondents who entered into cohabitation. An explanation could be that those in LAT relationships are generally restrained by the expectation that they will provide physical care for their partner or be the recipient of care from their partner (Bildtgård and Öberg 2015; Koren et al. 2016). In this view, higher age might be a source of worry with respect to future caregiving demands, facilitating the establishment of a relationship with separate households. Nonetheless, this interpretation should be taken with caution since the effect of age in the logistic regression was small.

It is also worth mentioning that LAT living arrangements were found to be more prevalent than cohabitation relationships, which contradicts previous work suggesting the opposite (Brown et al. 2016; De Jong Gierveld and Merz 2013; Lewin 2017; Wu et al. 2014). Except for the study by De Jong Gierveld and Merz (2013), the remaining research was conducted on different continents, suggesting cultural differences. Moreover, our findings were drawn from relatively recently collected data. Therefore, more research on the incidence of later-life LAT relationships in Europe is needed to build cumulative evidence as well as to reassess the stability of later-life LAT relationships. This would explain the dominance of this living arrangement over cohabitation relationships that are established in later life.

Several study limitations need to be taken into consideration. The relationship category for each individual had to be inferred from multiple existing variables. Some respondents were not included in the analyses due to missing or contradictory information. The cohabitation category included both unmarried and remarried cohabiters, which might have suppressed the potential for identifying the specifics of each group. Although we assessed bonding and dwelling features using several variables, these measurements constituted single items, which might have produced deviations. Furthermore, adopting a longitudinal approach resulted in the identification of a smaller number of older persons who established a new relationship in later life. Lastly, the LAT group was identified by a single item about having a partner outside the household without probing the level of relationship commitment. However, the SHARE project is the only available survey allowing for the longitudinal study of later-life relationship formation and preferences for specific relationship forms. 
To conclude, this study showed that the most influential determinants of later-life relationship formation include younger age, being male, and the lack of resource constraints. Older people who opted for a LAT living arrangement were more likely to report better health than those who remained unpartnered. This study suggests that older people opt for LAT living arrangements for reasons other than family bonds and resource constraints.

\section{References}

Asparouhov, Tihomir and Bengt Muthén. 2005. "Multivariate Statistical Modeling with Survey Data." Pp. 14-16 in Proceedings of the Federal Committee on Statistical Methodology (FCSM) Research Conference.

Asparouhov, Tihomir and Bengt Muthén. 2006. "Multilevel Modeling of Complex Survey Data." Pp. 2718-2726 in Proceedings of the Joint Statistical Meeting in Seattle. American Statistical Association.

Benson, Jacquelyn J. and Marilyn Coleman. 2016. "Older Adults Developing a Preference for Living Apart Together." Journal of Marriage and Family 78(3): 797-812.

Bildtgård, Torbjörn and Peter Öberg. 2015. "Time as a Structuring Condition behind New Intimate Relationships in Later Life." Ageing \& Society 35(7): 1505-1528.

Börsch-Supan, Axel. 2018. Data from: Survey of Health, Ageing and Retirement in Europe (SHARE) Wave 6. Release version: 6.1.0. [dataset]. SHARE-ERIC. Available from: https://doi.org/10.6103/ SHARE.w6.610.

Brown, Susan L., I-Fen Lin, Anna M.Hammersmith, and Mattew R. Wright. 2016. "Later Life Marital Dissolution and Repartnership Status: A National Portrait." The Journals of Gerontology Series Series B: gbw051.

Carstensen, Laura L., Derek M. Isaacowitz, and Susan T. Charles. 1999. "Taking Time Seriously: A Theory of Socio-Emotional Selectivity." American Psychologist 54(3): 165-181.

Connidis, Ingrid A., Klas Borell, and Sofie G. Karlsson. 2017. "Ambivalence and Living Apart Together in Later Life: A Critical Research Proposal." Journal of Marriage and Family 79(5): 1404-1418.

De Jong Gierveld, Jenny. 2002. "The Dilemma of Repartnering: Considerations of Older Men and Women Entering New Intimate Relationships in Later Life." Ageing International 27(4): 61-78.

De Jong Gierveld, Jenny. 2004. "Remarriage, Unmarried Cohabitation, Living Apart Together: Partner Relationships Following Bereavement or Divorce." Journal of Marriage and Family 66(1): 236-243.

De Jong Gierveld, Jenny. 2015. "Intracouple Caregiving of Older Adults Living Apart Together: Commitment and Independence." Canadian Journal on Aging 34(3): 356-365.

De Jong Gierveld, Jenny and Eva-Maria Merz. 2013. "Parents' Partnership Decision Making after Divorce or Widowhood: The Role of (Step) Children." Journal of Marriage and Family 75(5): 1098-1113.

Duncan, Simon, Julia Carter, Miranda Phillips, Sasha Roseneil, and Mariya Stoilova. 2012. "Legal Rights for People who 'Live Apart Together'?” Journal of Social Welfare and Family Law 34(4): 443-458.

Duncan, Simon, Julia Carter, Miranda Phillips, Sasha Roseneil, and Mariya Stoilova. 2013. "Why Do People Live Apart Together?" Families, Relationships and Societies 2(3): 323-338.

Eurostat. 2017a. "Population Structure and Ageing." Retrieved July 4, 2018 (http://ec.europa.eu/eurostat/ statisticsexplained/index.php/Population_structure_and_ageing). 
Eurostat. 2017b. "The Life of Women and Men in Europe: A Statistical Portrait." Retrieved July 4, 2018 (http://ec.europa.eu/eurostat/cache/infographs/womenmen/bloc-1a.html?lang=en).

Funk, Laura M. and Karen M. Kobayashi. 2016. "From Motivations to Accounts: An Interpretive Analysis of 'Living Apart Together' Relationships in Mid- to Later-Life Couples." Journal of Family Issues 37(8): 1101-1122.

Karlsson, Sofie G. and Klas Borell. 2002. "Intimacy and Autonomy, Gender and Ageing: Living Apart Together." Ageing International 27(4): 11-26.

Kobayashi, Karen. M., Laura Funk, and Mushira M. Khan. 2017. "Constructing a Sense of Commitment in 'Living Apart Together' (LAT) Relationships: Interpretive Agency and Individualization.” Current Sociology 65(7): 991-1009.

Koren, Chaya. 2014. "Together and Apart: A Typology of Re-Partnering in Old Age." International Psychogeriatrics 26(8): 1327-1350.

Koren, Chaya. 2015. "The Intertwining of Second Couplehood and Old Age." Ageing \& Society 35(9): 1864-1888.

Koren, Chaya and Shiran Simhi. 2016. ““As Long as it's Good': An Intergenerational Family Perspective of Bridging Gaps between Reality and Ideality of Second Couplehood as a Problem and as a Solution." Ageing \& Society 36(4): 716-740.

Koren, Chaya, Shiran Simhi, Sharon Lipman-Schiby, and Saray Fogel. 2016. "The Partner in LateLife Repartnering: Caregiving Expectations from an Intergenerational Perspective.” International Psychogeriatrics 28(9): 1555-1565.

Levin, Irene. 2004. "Living Apart Together: A New Family Form.” Current Sociology 52(2): 223-240.

Lewin, Alisa C. 2017. "Health and Relationship Quality Later in Life: A Comparison of Living Apart Together (LAT), First Marriages, Remarriages, and Cohabitation.” Journal of Family Issues 38(12): 1754-1774.

Malta, Sue and Karen Farquharson. 2014. "The Initiation and Progression of Late-Life Romantic Relationships.” Journal of Sociology 50(3): 237-251.

Malter, Frederic and Axel Börsch-Supan, eds. 2017. SHARE Wave 6: Panel Innovations and Collecting Dried Blood Spots. Munich: Munich Center for the Economics of Aging (MEA).

Očadlíková, Eva. 2009. "Láska na dvou adresách: Oddělené soužití v sociologických výzkumech [Love at Two Addresses: Living Apart Together in Sociological Research].” Sociální studia 6(4): 115-128.

Régnier-Loilier, Arnaud, Éva Beaujouan, and Villeneuve-Gohalp. 2009. "Neither Single, Nor in a Couple: A Study of Living Apart Together in France.” Demographic Research 21: 75-108.

Reimondos, Anna, Ann Evans, and Edith Gray. 2011. "Living Apart Together (LAT) Relationships in Australia." Family Matters 87: 43-55.

Schimmele, Christoph M. and Zheng Wu. 2016. "Repartnering after Union Dissolution in Later Life." Journal of Marriage and Family 78(4): 1013-1031.

Schoon, Ingrid, Helen Cheng, Catharine R. Gale, G. David Batty, and Ian J. Deary. 2010. "Social Status, Cognitive Ability, and Educational Attainment as Predictors of Liberal Social Attitudes and Political Trust." Intelligence 38(1): 144-150.

Ševčíková, Anna, Jana Lichá, and Kateřina Škařupová. 2018. "Navazování vážného vztahu v pozdním věku: představy a obavy [Establishing Serious Partner Relationship in Late Life: Ideas and Worries]." Československá psychologie 62(5): 513-525.

Strohm, Charles Q., Judith A. Seltzer, Susan D. Cochran, and Vickie M. Mays. 2009. "Living Apart Together: Relationships in the United States." Demographic research 21(7): 177-214.

Turcotte, Martin. 2013. Insights on Canadian Society: Living Apart Together. Statistics Canada 75-006-X. Retrieved October 2, 2020 (http://www.statcan.gc.ca/pub/75-006-x/2013001/article/11771-eng. htm). 
Upton-Davis, Karen. 2012. "Living Apart Together Relationships (LAT): Severing Intimacy from Obligation." Gender Issues 29(1-4): 25-38.

Vespa, Jonathan. 2012. "Union Formation in Later Life: Economic Determinants of Cohabitation and Remarriage among Older Adults." Demography 49(3): 1103-1125.

Wu, Zheng, Christoph M. Schimmele, and Nadia Ouellet. 2014. "Repartnering after Widowhood." Journals of Gerontology Series B: Psychological Sciences and Social Sciences 70(3): 496-507.

\section{Authors}

Anna Ševčíková is a senior researcher fellow at the Faculty of Social Studies, Masaryk University. She studies the various psychological aspects of Internet use for sexual purposes. She also focuses on researching the changes in forms of sexual expressions and relationships in older age from a developmental perspective.

Contact: asevciko@fss.muni.cz

Dana Seryjová Juhová is a PhD student at the Faculty of Social Studies, Masaryk University. Her interests include topics related to developmental psychology (e.g. attachment and relationships in older age), educational psychology (e.g. student-teacher relationships), as well as the development of diagnostic methods.

Contact: juhova@fss.muni.cz

Adam Ť́a $a$ al is a researcher focusing on psychometrics and the application of latent variable models. His interests are rather broad, ranging from topics in applied psychological measurement to response styles modelling.

Contact:adam.tapal@gmail.com

Lukas Blinka is a researcher and assistant professor at the Faculty of Social Studies, Masaryk University. His research focuses on topics related to health and media, the psychology of addictions, and the psychology of sexuality.

Contact: blinka@fss.muni.cz

Jaroslav Gottfried is a researcher at the Faculty of Social Studies, Masaryk University. He focuses on methodology of psychological research, as well as statistical analysis in psychology and psychometrics.

Contact: jaroslav.gottfried@mail.muni.cz 